\title{
Experimental Investigation of Tension Stiffening in RC Ties
}

\author{
Aleksandr Sokolov, ${ }^{1}$ Gintaris Kaklauskas, ${ }^{1,2}$ Ronaldas Jakubovskis, ${ }^{1,2}$ Mantas Juknys, ${ }^{2}$ \\ Romualdas Kliukas, ${ }^{3}$ Pui Lam Ng, ${ }^{2,4}$ and Viktor Gribniak ${ }^{1,2}$ \\ ${ }^{1}$ Research Laboratory of Innovative Building Structures, Vilnius Gediminas Technical University (VGTU), LT-10223 Vilnius, Lithuania \\ ${ }^{2}$ Department of Bridges and Special Structures, VGTU, LT-10223 Vilnius, Lithuania \\ ${ }^{3}$ Department of Strength of Materials and Engineering Mechanics, VGTU, LT-10223 Vilnius, Lithuania \\ ${ }^{4}$ Department of Civil Engineering, The University of Hong Kong, Pok Fu Lam, Hong Kong
}

Correspondence should be addressed to Gintaris Kaklauskas; gintaris.kaklauskas@vgtu.lt

Received 23 May 2016; Accepted 15 September 2016

Academic Editor: Philip Eisenlohr

Copyright (C) 2016 Aleksandr Sokolov et al. This is an open access article distributed under the Creative Commons Attribution License, which permits unrestricted use, distribution, and reproduction in any medium, provided the original work is properly cited.

\begin{abstract}
The increasing application of high-performance materials in civil engineering led to the development of reinforced concrete (RC) structures with reduced cross sections and increased spans. In such structures serviceability limit state often becomes the governing condition of the design. Present study investigates the deformation behaviour of high-strength RC ties reinforced with high-grade bars. Experimental investigation was carried out measuring the postcracking stiffness of the specimens at high strain levels. It was found that, despite the reduction in stiffness, a considerable part of the average tensile stresses were carried by the concrete at the advanced loading stages, thus effectively stiffening the RC member.
\end{abstract}

\section{Introduction}

Application of high-strength concrete in RC structures allows for design members with increased spans and reduced cross section dimensions; however, this may lead to reinforcing bar congestion, difficulties in reinforcement detailing, and concrete casting. In this respect, the use of high-grade steel bars may be advantageous, as it can reduce the required amount of reinforcement up to $30-40 \%$ while maintaining the same load bearing capacity of the structure [1].

Due to increasing demand of high-performance materials for structural applications, a number of investigations have been carried out in the last decades concerning the use of high-strength reinforcement. Most of the research studies were dedicated to the analysis of the ultimate limit states: shear strength of large concrete beams [2], bond characteristics of lapped splices [3,4], and load bearing capacity of flexural members and bridge decks $[5,6]$.

In these studies, high-grade steel was used with the strength between 690 and $827 \mathrm{MPa}$. As the elasticity modulus of the high-grade steel is almost identical to conventional steel bars, strain in reinforcement may be up to 2 times higher in comparison with conventional reinforcing steel. This may result in excessive crack widths and deflections, especially in slender high-strength concrete elements. Moreover, reducing the amount of ordinary reinforcement and replacing it by high-grade bars would inevitably result in decreased stiffness of the structure. Thus, the serviceability criteria may limit the application of high-performance materials in RC structures, especially when the span to depth ratio is relatively large.

Regarding serviceability behaviour of high-strength concrete elements, quite controversial results have been obtained. Abrishami and Mitchell [7] tested 10 tensile RC elements of normal-strength $\left(f_{c}=35 \mathrm{MPa}\right)$ and high-strength $\left(f_{c}=90 \mathrm{MPa}\right)$ concrete. It was concluded that the tensile response (effect of tension stiffening) of the high-strength concrete specimens was similar to that of the normal-strength concrete specimens. In the study of Lee and Kim [8], it was found that the postcracking stiffness of tensile RC elements was significantly lower for high-strength $\left(f_{c}=80 \mathrm{MPa}\right)$ concrete specimens in comparison with normal-strength $\left(f_{c}=25 \mathrm{MPa}\right)$ concrete. Such behaviour contradicts the experimental findings of Lorrain et al. [9], where greater tension stiffening effect was observed for high-strength concrete 
$\left(f_{c}=100 \mathrm{MPa}\right)$ specimens, which is also supported by the common design approaches $[10,11]$, where the postcracking stiffness is proportional to the concrete tensile strength.

The source of contradictions may be attributed to the influence of shrinkage on tension stiffening [12], as no detailed information was provided in the mentioned studies. Influence of shrinkage could be even more significant in case of high-strength concrete, if a large paste volume is adopted in the mix design, where the autogenous part generally accounts for a considerable portion of the total shrinkage strain [13].

From the analysis of experimental work done so far, it may be also evident that existing test data on cracking and deformation behaviour of RC members is limited up to $0.2-0.25 \%$ strain, which corresponds to the yield stresses of ordinary steel bars $\left(f_{y}=400-500 \mathrm{MPa}\right)$ [14]. Deformation and cracking beyond this limit have been studied as postyield behaviour of RC tensile elements [15]. However, for highgrade bars, strain rate of $0.25-0.4 \%$ is attainable under elastic regime in the serviceability condition, and thus the deformation behaviour is completely different from the postyield stage [16].

It was also reported experimentally that the stiffness of RC elements tends to decrease with increasing load and strain in the reinforcement [17]. Such behaviour is generally explained by the gradual damage of bond and development of splitting cracks [15]. These effects could be even more detrimental for high-grade steel due to much higher strains; however, there is lack of experimental evidence to prove this postulation.

The present study focuses on deformation behaviour of $\mathrm{RC}$ tensile elements reinforced with high-grade bars. The effect of high strain on average deformation, deterioration of bond, and stiffness was experimentally investigated based on $\mathrm{RC}$ tensile elements. To evaluate the influence of shrinkage, precise measurements of free shrinkage strain of concrete were performed and the effect was numerically estimated.

\section{Experimental Program}

2.1. Test Specimens. The experimental investigation involves four RC ties of $650 \mathrm{~mm}$ in length with $100 \times 100 \mathrm{~mm}$ cross section and contained a single reinforcing bar of $12 \mathrm{~mm}$ in diameter placed longitudinally through the centroid of each cross section, as shown in Figure 1. The tensile axial load was applied to the ends of the reinforcing bar protruding from each end of the concrete tie. The specimens were grouped into two series. The ties of the first series (T12-1 and T12-2) were cured in normal laboratory conditions (relative humidity, $42.9 \%$, and temperature, $20.2^{\circ} \mathrm{C}$, on average), whereas ties of the second series (T12-1w and T12-2w) were cured in the water tank to minimize the effect of shrinkage. Main parameters of the test ties are listed in Table 1. The following notations are defined: concrete area $\left(A_{c}\right)$, diameter of reinforcing bar $(\varnothing)$, steel area $\left(A_{s}\right)$, steel reinforcement ratio $(\rho)$, age of the specimens at the testing day $(t)$, and compressive strength of $150 \mathrm{~mm}$ concrete cube $\left(f_{\text {cube }}\right)$.

2.2. Material Properties. This investigation considers concrete mix given in Table 2. Portland cement and locally available crushed sandstone with a maximal nominal size of

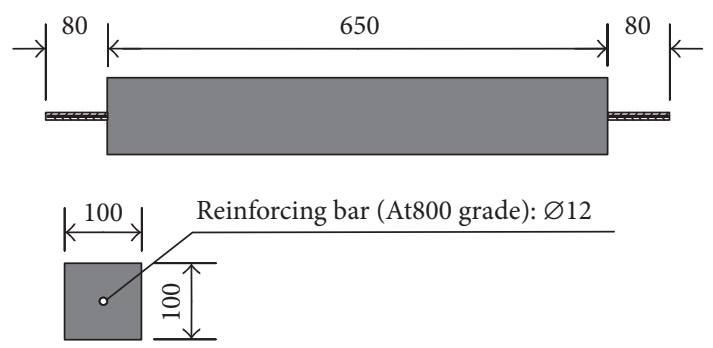

FIGURE 1: Details of the specimens.

$16 \mathrm{~mm}$ were used as the coarse aggregate. The water/cement ratio by weight was adopted as 0.36 , while the aggregate/cement ratio was 2.49. All specimens were cast using steel formwork. The specimens were demoulded 2 days after casting.

The concrete compressive strength was measured at the age of 28 days based on $150 \mathrm{~mm}$ cube specimens, and the average result obtained was 77.2 $\mathrm{MPa}$. Prior to the short-term tests of the ties, measurement of concrete shrinkage was performed using $400 \mathrm{~mm}$ prismatic concrete specimens, which represented fragments of the experimental ties. The shrinkage measurements at the $200 \mathrm{~mm}$ base were performed using the surface-glued steel gauge studs. A detailed explanation of the measurement technique is presented in [18]. The variation of shrinkage strain with time is shown in Figure 2.

Reinforcement consisted of high-grade deformed bars with nominal diameter of $\varnothing 12 \mathrm{~mm}$. The steel grade was conforming to At800. Three samples were tested and several lengths were weighed to check the nominal size. The stresses and modulus of elasticity are based on nominal diameters. The obtained average yield stress of the bars was $945 \mathrm{MPa}$, whereas ultimate strength was equal to $1120 \mathrm{MPa}$. The determined elastic modulus of the bars was $190 \mathrm{GPa}$.

2.3. Test Procedure and Results. The ties were tested under monotonically increasing displacement up to yielding of the reinforcing steel bar using a displacement-controlled machine with $100 \mathrm{kN}$ capacity. The loading rate was $0.1 \mathrm{~mm} /$ min. The strain in internal reinforcement was measured by linear variable displacement transducers (LVDT) (Figure 3) and recorded throughout the testing process.

The obtained average strain versus applied load diagrams is presented in Figure 4 together with the bare bar response for the specimen. At any load level, the difference in strain between the specimen and the bare bar reflects the effect of tension stiffening and it represents the contribution of the concrete to the member stiffness.

All the specimens have an initial ascending branch with a steep slope corresponding to the uncracked condition. After cracking load $\left(P_{\mathrm{cr}}\right)$ is reached, a drop in the slope is observed due to the progressive cracking of the element. At this stage, the load-strain response gradually tends towards fully cracked behaviour.

From Figure 4, it can be seen that the cracking load of the water-cured specimens (T12-1w and T12-2w) was higher in comparison with the air-cured specimens, T12-1 
TABLE 1: Main characteristics of the test ties.

\begin{tabular}{|c|c|c|c|c|c|c|c|c|c|c|}
\hline Series & Ties & $h \times b$ & $L$ & $\begin{array}{c}A_{c} \\
\mathrm{~mm}^{2}\end{array}$ & $\begin{array}{c}\varnothing \\
\mathrm{mm}\end{array}$ & $\begin{array}{c}A_{s} \\
\mathrm{~mm}^{2}\end{array}$ & $\begin{array}{l}\rho \\
\%\end{array}$ & $\begin{array}{c}t \\
\text { Days }\end{array}$ & $\begin{array}{l}f_{\text {cube }} \\
\mathrm{MPa}\end{array}$ & Steel grade \\
\hline I & $\begin{array}{l}\text { T12-1 } \\
\text { T12-2 }\end{array}$ & $100 \times 100$ & 650 & 9921 & 12 & 113.1 & 1.13 & $\begin{array}{l}198 \\
199\end{array}$ & 77.2 & At800 \\
\hline II & $\begin{array}{l}\text { T12-1w } \\
\text { T12-2w }\end{array}$ & $100 \times 100$ & 650 & 9886 & 12 & 113.1 & 1.13 & $\begin{array}{l}198 \\
199\end{array}$ & 77.2 & At800 \\
\hline
\end{tabular}

TABLE 2: Mixture proportion of the test specimens $\left(\mathrm{kg} / \mathrm{m}^{3}\right)$.

\begin{tabular}{lc}
\hline Material & Amount \\
\hline Sand, 0/2 mm & $277 \pm 1 \%$ \\
Sand, 0/4 mm & $457 \pm 1 \%$ \\
Crushed aggregate, $5 / 8 \mathrm{~mm}$ & \\
Crushed aggregate, $8 / 11 \mathrm{~mm}$ & $1080 \pm 2 \%$ \\
Crushed aggregate, $11 / 16 \mathrm{~mm}$ & \\
Cement, CEM II, $42.5 \mathrm{R}$ & $433 \pm 0.5 \%$ \\
Water & $156 \pm 3 \%$ \\
Concrete plasticizer, MC-PowerFlow & $8.50 \pm 1.8 \%$ \\
\hline
\end{tabular}

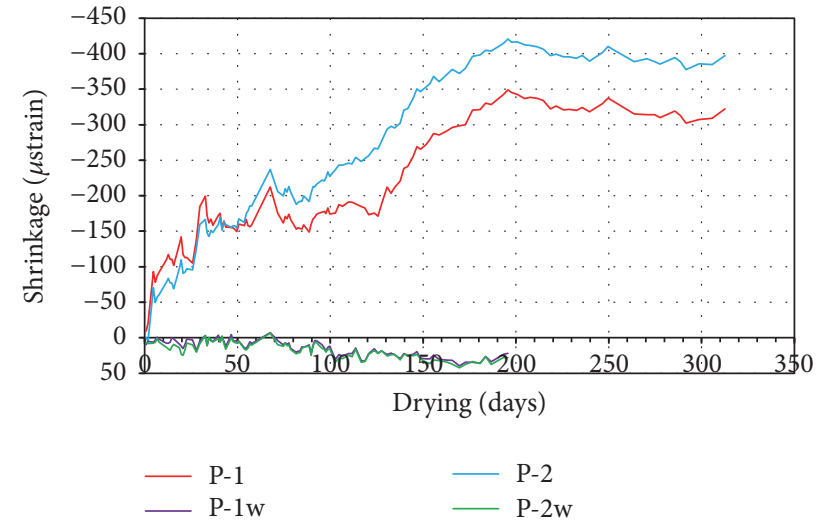

Figure 2: Development of concrete shrinkage.

and $\mathrm{T} 12-2\left(P_{\mathrm{cr}} \approx 44 \mathrm{kN}\right.$ and $38 \mathrm{kN}$, resp.). The postcracking stiffness was also higher in water-cured specimens. This effect can be mainly attributed to the influence of shrinkage on cracking resistance and tension stiffening $[12,19]$. Concrete shrinkage strain in the air-cured specimens reached about 350-400 $\mu \varepsilon$ value, which corresponded to self-induced tensile stresses of about $0.9 \mathrm{MPa}$. Such stresses resulted in earlier cracking of the air-cured specimens and the reduced effect of tension stiffening in the postcracking stage. Enhancement of cracking resistance may be also related to the difference in the curing conditions. Study by Atis et al. [20] has shown that compressive strength of concrete under saturated conditions increases; however, it was not directly related to the tensile strength. In present study, only the effect of shrinkage was evaluated.

To assess the effect of shrinkage, a numerical technique previously proposed in [19] was applied to all tested specimens. The obtained free-of-shrinkage diagrams (denoted as

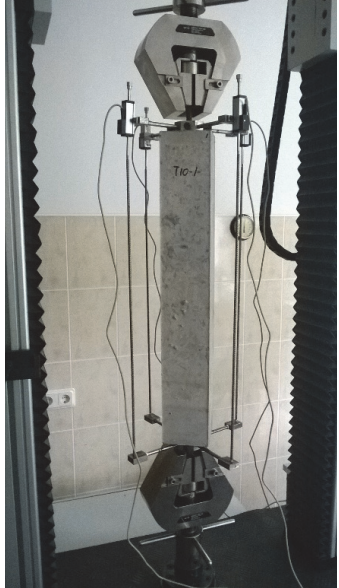

FIgURE 3: Test set-up.

Test_sh) are shown in Figure 5. These diagrams are further used in the analysis.

\section{Theoretical Modelling}

To model the deformation behaviour of the experimental specimens, three approaches were employed: design methodologies of Model Code 1990 [10] and Model Code 2010 [11] and the stress transfer approach presented in [21].

Model Code 1990 [10] proposes to distinguish the loaddisplacement diagram of the tensile $\mathrm{RC}$ element in four regions: uncracked, crack formation, stabilized cracking, and postyield (Figure 6(a)). The increase in strain of the element $\left(\Delta \varepsilon_{\mathrm{sm}}\right)$ is evaluated using strain of reinforcement in the cracked $\left(\varepsilon_{\mathrm{sr} 2}\right)$ and uncracked $\left(\varepsilon_{\mathrm{sr} 1}\right)$ concrete:

$$
\Delta \varepsilon_{\mathrm{sm}}=\beta\left(\varepsilon_{\mathrm{sr} 2}-\varepsilon_{\mathrm{sr} 1}\right),
$$

where $\beta$ is a factor taken as 0.6 for crack formation stage and as 0.4 for stabilized cracking stage.

The recent version of Model Code 2010 [11] uses the approach to calculate average strain of an element by interpolating between two states, uncracked (region 1) and fully cracked, or bare bar response (region 2) (Figure 6(b)). In region 1 , both the concrete and steel behave elastically, while in region 2 the reinforcing steel carries all the tensile force in the member after cracking. The average deformation is expressed as

$$
\varepsilon_{m}=\varepsilon_{1}(1-\xi)+\xi \varepsilon_{2}
$$




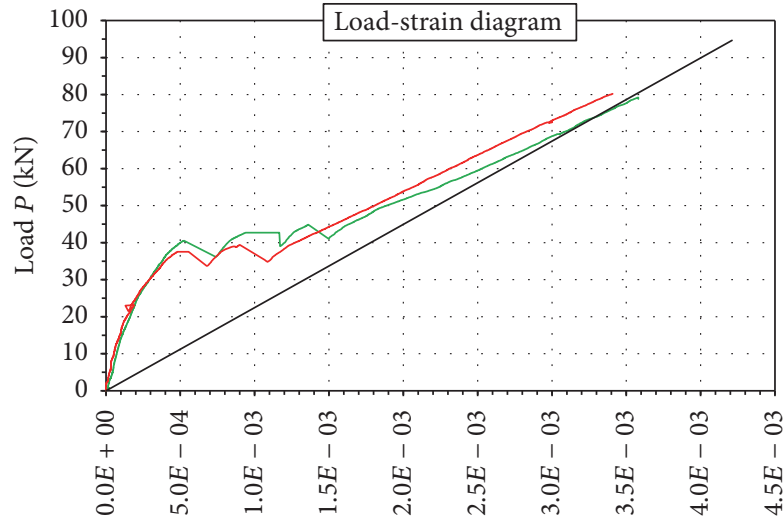

Strain $\varepsilon$

— T12-1

— T12-2

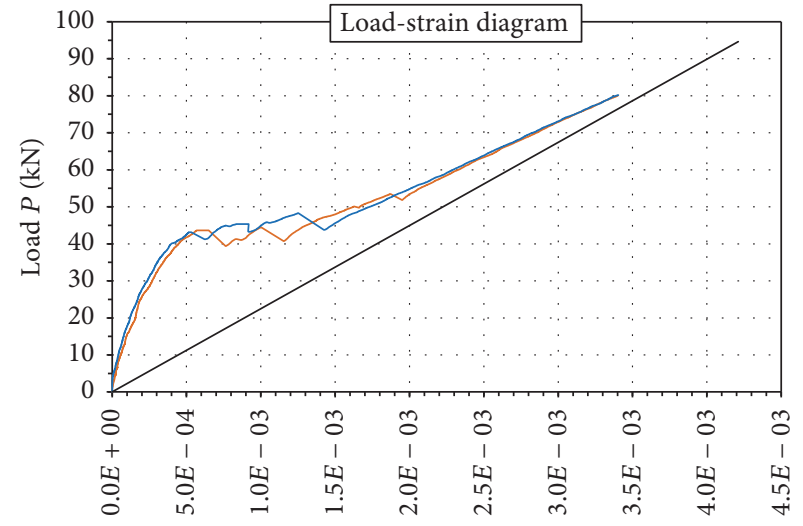

Strain $\varepsilon$

T12-1w

T12-2W

FIGURE 4: Experimental load-strain relation of the ties.

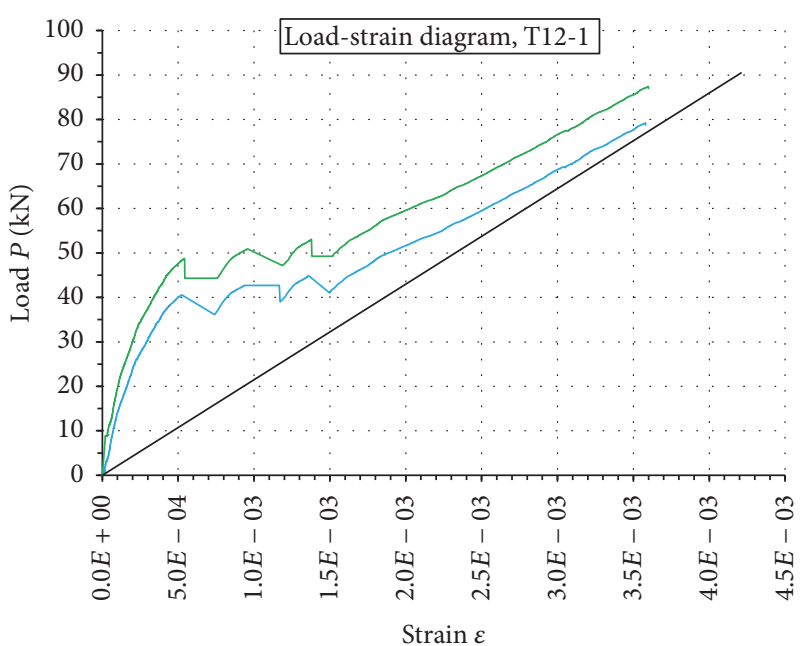

_ Test

_ Test_sh

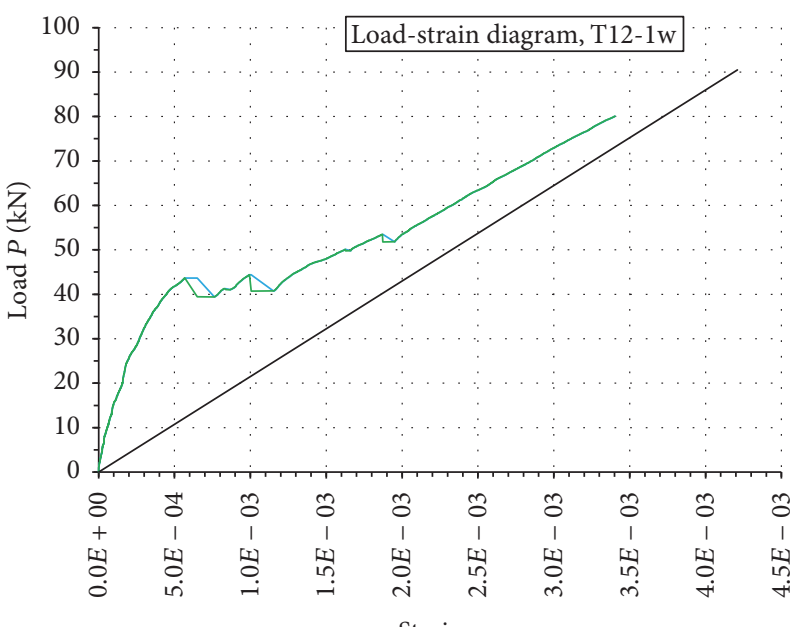

Strain $\varepsilon$

- Test

— Test_sh

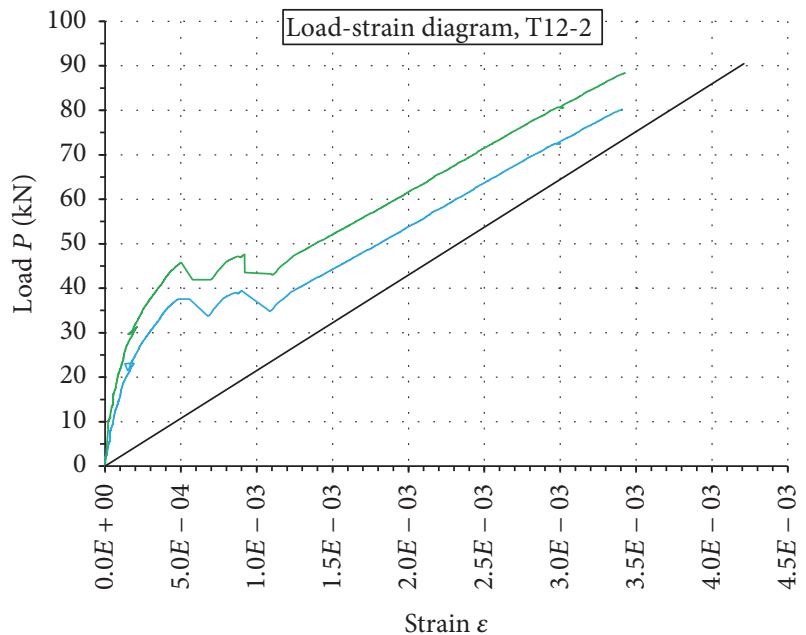

_ Test

_ Bare bar

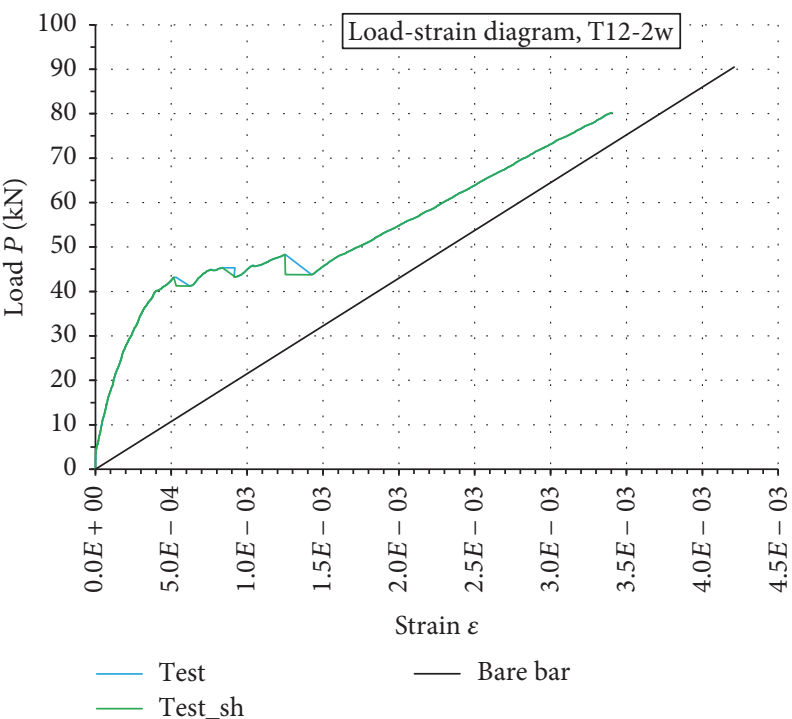

FIGURE 5: Free-of-shrinkage diagrams. 

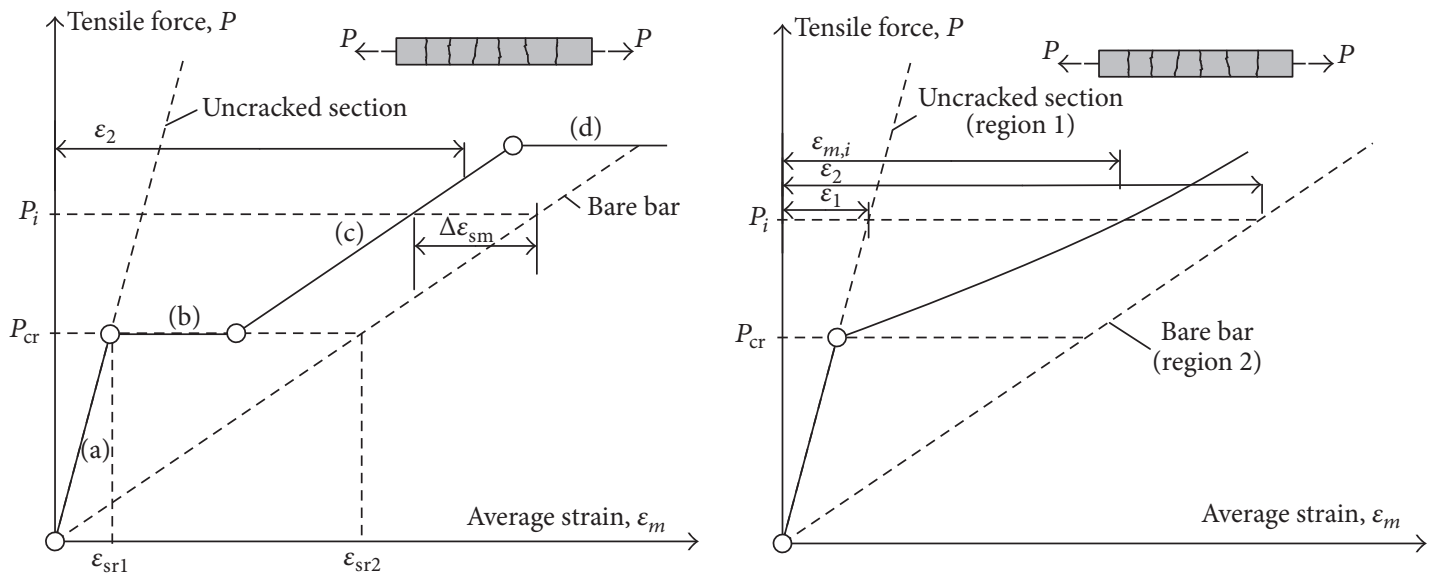
(a) Uncracked
(b) Crack formation
(c) Stabilized cracking
(d) Postyielding

(a)

(b)

FIGURE 6: Load-average strain models according to Model Code 1990 [10] (a) and Model Code 2010 [11] (b).

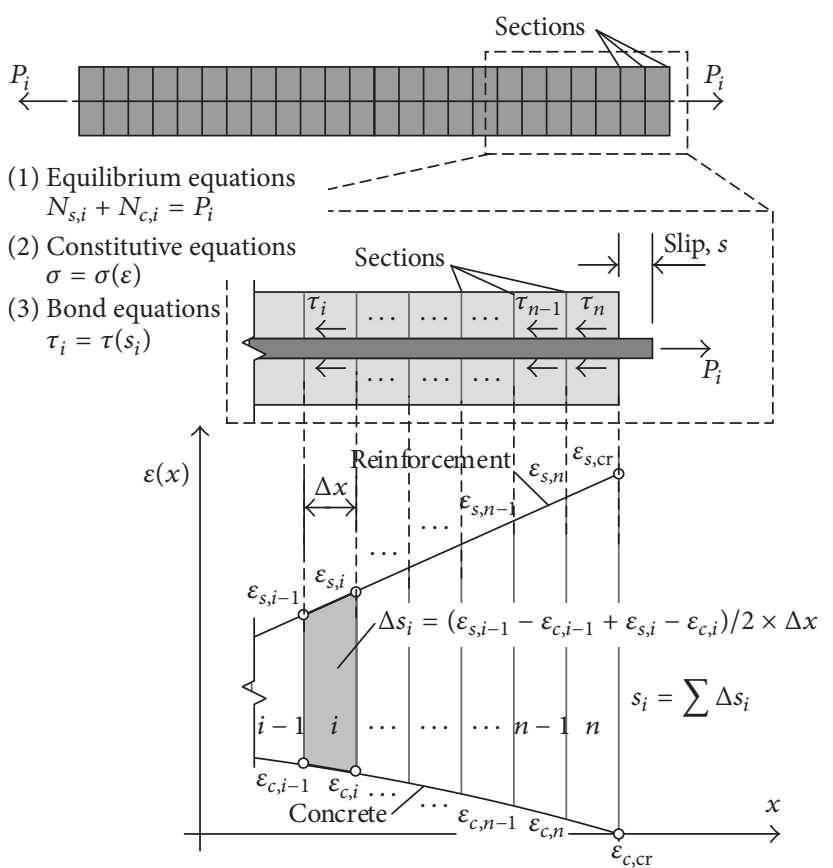

FIGURE 7: Stress transfer algorithm.

In (2), $\varepsilon_{1}$ and $\varepsilon_{2}$ correspond to the strains in regions 1 and 2 , respectively. A coefficient $\xi$ indicates how close the stressstrain state is to the condition causing cracking. It takes a value of zero at the cracking moment and approaches unity as the loading increases beyond the cracking load:

$$
\xi=1-\beta\left(\frac{P_{\mathrm{cr}}}{P}\right)^{2} .
$$

Here, $\beta$ is a factor taken as 1.0 for the case of short-term loading; $P_{\mathrm{cr}}$ and $P$ are the cracking and the applied load, respectively.
The third approach is to model the deformational behaviour of the experimental elements using the principles of the stress transfer algorithms $[15,22]$. The stress transfer models are based on the local interaction of reinforcement to concrete and are able to realistically model both cracking and deformation behaviours of RC members. Authors of the present paper have further refined this approach introducing the stochastic formation of cracks and progressively increasing damage zone [21].

Consider the RC element in tension, shown in Figure 7. The element is divided into a number of sections, $n$. By incrementally applying load $P$, three equation groups (equilibrium, constitutive, and bond) are iteratively solved simultaneously in all sections until the boundary conditions are satisfied. Special boundary conditions in connection with concrete and reinforcement stress, strain, and slip values are introduced depending on the load level and the length of the cracked element.

During the analysis, stresses and strains in reinforcement and concrete as well as interfacial slip and bond stresses are calculated along the element at each load step. From the obtained stress and strain profiles, it is possible to simulate the formation of cracks and deformation behaviour of the specimen. Integrating the reinforcement strain profile along the element, the full load-displacement diagram can be obtained.

The detailed analysis algorithm of the developed stress transfer approach is described in detail in [21]. Some of the aspects used in the present study are emphasized below.

(1) Bond-slip model proposed by Model Code 2010 [11] was employed in the stress transfer algorithm:

$$
\tau(s)=\tau_{\max }\left(\frac{s}{s_{1}}\right)^{\alpha},
$$




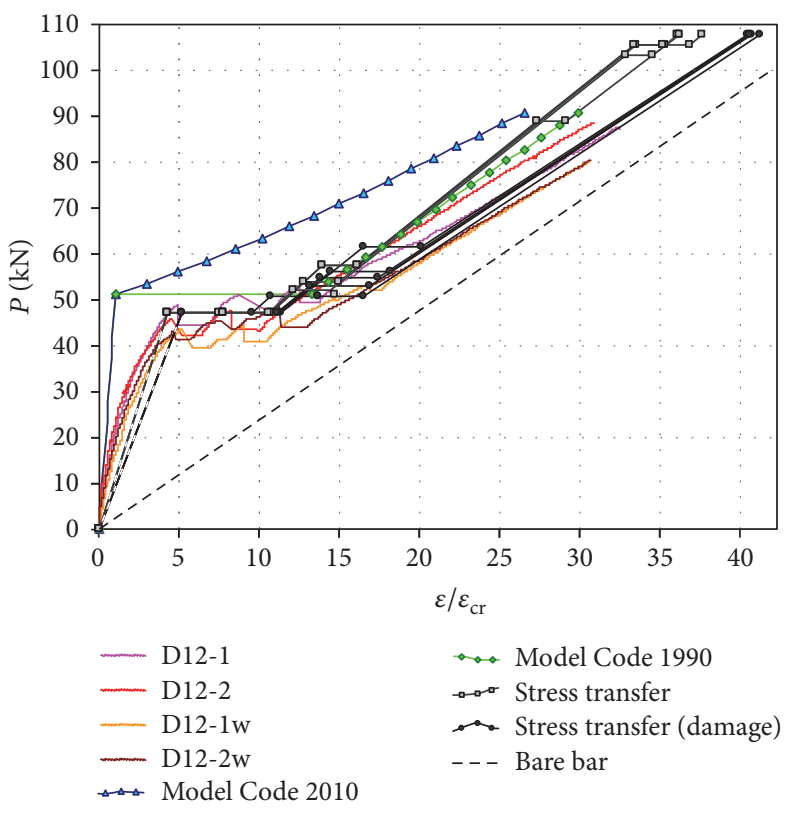

(a)

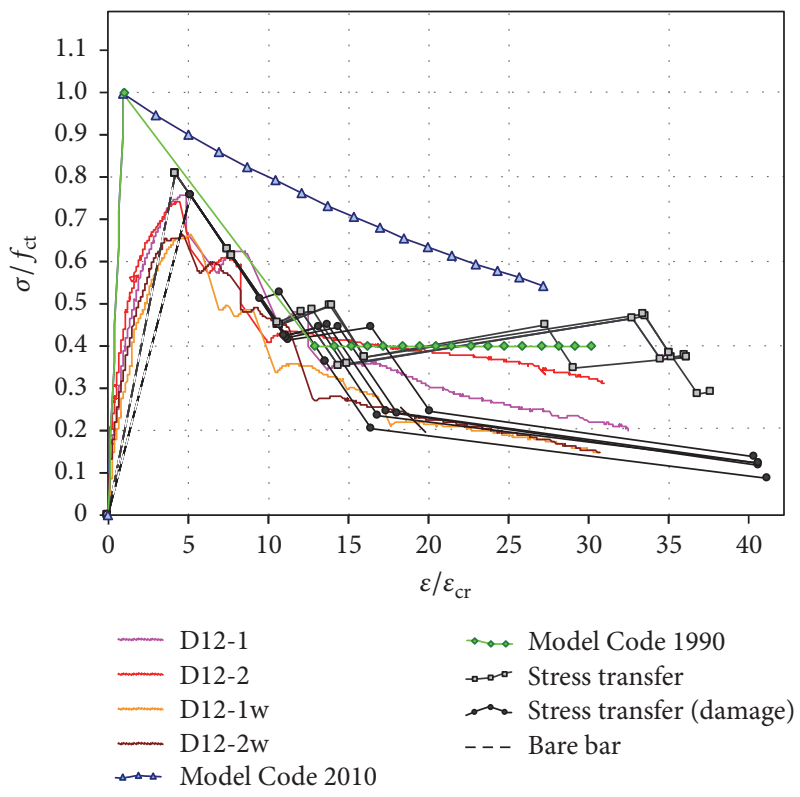

(b)

FIgURE 8: Theoretical modelling of RC ties: (a) load-average strain diagrams; (b) average stress-average strain diagrams.

where $\tau_{\max }$ is the maximal bond stress; $\alpha$ is the exponential index; $s_{1}$ is the slip value corresponding to the maximal bond stress.

Model Code 2010 [11] allows us to simulate a wide range of possible bond-slip relationships, depending on the exponential index $\alpha$ : from rigid $(\alpha=0)$ to linear $(\alpha=1)$. From a previous analysis of experimental results using the stress transfer approach $[21,23]$ and numerical modelling of cracking and deformation of the present RC ties, it was found that the value $\alpha=0.3$ assures adequate results with respect to the number of cracks and stiffness of the member.

(2) The local damage effect of bond near the cracks has a significant influence both on crack formation and on global stiffness of the RC element [24]. In present study, the model proposed in [21] is adopted. According to this model, full damage of bond is assumed near the cracks; that is, bond stresses suddenly drop to zero at distance $l_{d}$ from the crack plane $\left(l_{d}\right.$ is denoted as damage zone). The length of damage zone is proportional to bar diameter $\phi$ and strain in reinforcement $\varepsilon_{s}$ :

$$
l_{d}=1000 \cdot \varepsilon_{s} \cdot \phi
$$

To evaluate the influence of bond deterioration on the deformation behaviour of the tested specimens, the developed stress transfer algorithm was adopted with and without the damage zone (see (5)). Due to the random formation of cracks, the load-average strain diagram was simulated 5 times repeatedly for each case to better represent the deformation behaviour.

\section{Results and Discussion}

The deformation analysis approaches as discussed in the previous section were adopted for load-average strain predictions of the experimental specimens. Figure 8(a) shows the calculated load-average strain diagrams. The elastic branches of the theoretical load-strain diagrams were obtained by connecting zero and respective cracking points. The respective tension stiffening relations are shown in Figure 8(b). The latter were obtained as the average stress-average strain relations of concrete in tension dividing the average force acting in concrete by the cross section area of concrete. The tension stiffening relationships were normalized by dividing stresses by the tensile strength and the strains by the cracking strain.

From the obtained results, it may be seen that the initial ascending branch of the experimental curves had a strongly nonlinear character, which was mostly attributed to the chosen measurement technique. As the displacement was measured at the reinforcement, the occurrence of slip at the ends of the specimen resulted in higher strains at the ends of the member compared to the strains in the middle part representing fully composite action with perfect bond. This effect is apparent from the comparison of the experimental results and the design code predictions (referred to as Model Code 1990 and Model Code 2010). The effect of end slip was simulated using the stress transfer approach: in this case, the initial stiffness of the specimens was closer to the experimental behaviour. The effect of end slip also resulted in the mean maximal stress lower than the cracking stress of concrete. Under the conditions of perfect bond, concrete tensile strength is attained in all sections along the element 
with the normalized tensile stresses equal to unity $\left(\sigma / f_{\mathrm{ct}}=1\right)$. However, in reality stress, concrete at the ends of the specimen gradually increases towards the mid-section from zero up to the tensile strength reached at the transfer length. This effect can be well modelled by the stress transfer approach, as can be seen in Figure 8(a), where maximal normalized stresses are below unity, representing the normalized tensile strength of concrete.

From the computed load-average strain diagrams, it may be observed that both design code methods overestimated the stiffness of the experimental specimens, especially at the advanced loading stages. This may be attributed to the fact that the theoretical models do not take into account progressive formation of splitting cracks causing deterioration of bond at high strain levels. This can be taken into account by the stress transfer approach using the damage zone model (see (5)). As can be seen from the normalized tension stiffening diagrams (Figure 8(b)), the simulated average force in concrete decreased with increasing strain and it was also characteristic of the experimental curves. However, although stiffness of the experimental elements tended to decrease, a considerable part of average tensile stresses in concrete $\left(\sigma / f_{\text {ct }} \approx 0.2\right)$ still was present at strain levels up to $30-35 \varepsilon_{\text {cr }}$.

\section{Conclusions}

The following conclusions may be drawn from this study:

(1) Existing test data on cracking and deformation behaviour of RC members is limited up to $0.2-0.25 \%$ strain level, which corresponds to the stresses of ordinary steel bars: $f_{y}=400-500 \mathrm{MPa}$. The present study provides new experimental data combining the uses of high-performance materials: high-strength concrete $\left(f_{c}=77 \mathrm{MPa}\right)$ reinforced with high-grade steel bars $\left(f_{y}=945 \mathrm{MPa}\right)$.

(2) Experimental study has shown that the effect of tension stiffening tends to decrease at high strain levels. However, a considerable part of average tensile stresses in concrete $\left(\sigma / f_{\text {ct }} \approx 0.2\right)$ still exists at strain levels up to $30-35 \varepsilon_{\text {cr }}$.

(3) Precise measurements of shrinkage strain are required to evaluate the shrinkage influence on tension stiffening. It was shown that the shrinkage influence can be eliminated from the experimental load-average strain diagrams using the experimental shrinkage values along with numerical algorithm developed by the authors.

(4) The local effect of bond deterioration near the cracks has a significant influence on the global stiffness of the RC element. In the present study, it has been shown that the decreasing stiffness of the specimens using the stress transfer algorithm can be simulated by the so-called damage zone model (see (5)).

\section{Competing Interests}

The authors declare that they have no competing interests.

\section{Acknowledgments}

The authors gratefully acknowledge the financial support provided by the Research Council of Lithuania (Research Project no. MIP-093/2015).

\section{References}

[1] H. M. Seliem, Behavior of concrete bridges reinforced with highperformance steel reinforcing bars [Ph.D. thesis], 2007.

[2] T. K. Hassan, H. M. Seliem, H. Dwairi, S. H. Rizkalla, and P. Zia, "Shear behavior of large concrete beams reinforced with highstrength steel," ACI Structural Journal, vol. 105, no. 2, pp. 173179, 2008.

[3] R. El-Hacha, H. El-Agroudy, and S. H. Rizkalla, "Bond characteristics of high-strength steel reinforcement," ACI Structural Journal, vol. 103, no. 6, pp. 771-782, 2006.

[4] H. M. Seliem, A. Hosny, S. Rizkalla et al., "Bond characteristics of ASTM A1035 steel reinforcing bars," ACI Structural Journal, vol. 106, no. 4, pp. 530-539, 2009.

[5] M. B. Giduquio, M.-Y. Cheng, and L. S. B. Wibowo, "Highstrength flexural reinforcement in reinforced concrete flexural members under monotonic loading," ACI Structural Journal, vol. 112, no. 6, pp. 793-804, 2015.

[6] H. Seliem, G. Lucier, S. Rizkalla, and P. Zia, "Behaviour of concrete bridge decks reinforced with high-strength steel," in HPC: Build Fast, Build to Last. The 2006 Concrete Bridge Conference, 2006.

[7] H. H. Abrishami and D. Mitchell, "Influence of splitting cracks on tension stiffening," ACI Structural Journal, vol. 93, no. 6, pp. 703-710, 1996.

[8] G.-Y. Lee and W. Kim, "Cracking and tension stiffening behavior of high-strength concrete tension members subjected to axial load," Advances in Structural Engineering, vol. 12, no. 2, pp. 127-137, 2009.

[9] M. Lorrain, O. Maurel, and M. Seffo, "Cracking behavior of reinforced high-strength concrete tension ties," ACI Structural Journal, vol. 95, no. 5, pp. 626-635, 1998.

[10] CEB-FIP Model Code 90, 1991. Final Draft, Thomas Telford, London, UK, 1992.

[11] CEB-FIP Bulletin No.65. Model Code 2010. Final draft-vol 1, Lausanne, International Federation of Structural Concrete, 2012.

[12] G. Kaklauskas, V. Gribniak, D. Bacinskas, and P. Vainiunas, "Shrinkage influence on tension stiffening in concrete members," Engineering Structures, vol. 31, no. 6, pp. 1305-1312, 2009.

[13] J. Zhang, Y. D. Han, Y. Gao, and Y. Luosun, "Integrative study on the effect of internal curing on autogenous and drying shrinkage of high-strength concrete," Drying Technology, vol. 31, no. 5, pp. 565-575, 2013.

[14] V. Gribniak, H. A. Mang, R. Kupliauskas, and G. Kaklauskas, "Stochastic tension-stiffening approach for the solution of serviceability problems in reinforced concrete: constitutive modeling," Computer-Aided Civil and Infrastructure Engineering, vol. 30, no. 9, pp. 684-702, 2015.

[15] H. Salem and K. Maekawa, "Spatially averaged tensile mechanics for cracked concrete and reinforcement in highly inelastic range," Concrete Library of JSCE, vol. 34, pp. 151-169, 1999.

[16] M. F. Ruiz, A. Muttoni, and P. G. Gambarova, "Analytical modeling of the pre- and postyield behavior of bond in reinforced 
concrete," Journal of Structural Engineering, vol. 133, no. 10, pp. 1364-1372, 2007.

[17] H. Q. Wu and R. I. Gilbert, "Modeling short-term tension stiffening in reinforced concrete prisms using a continuumbased finite element model," Engineering Structures, vol. 31, no. 10, pp. 2380-2391, 2009.

[18] V. Gribniak, Shrinkage influence on tension-stiffening of concrete structures [Ph.D. thesis], Vilnius Gediminas Technical University, Vilnius, Lithuania, 2009.

[19] G. Kaklauskas and V. Gribniak, "Eliminating shrinkage effect from moment curvature and tension stiffening relationships of reinforced concrete members," Journal of Structural Engineering, vol. 137, no. 12, pp. 1460-1469, 2011.

[20] C. D. Atiş, F. Özcan, A. Kiliç, O. Karahan, C. Bilim, and M. H. Severcan, "Influence of dry and wet curing conditions on compressive strength of silica fume concrete," Building and Environment, vol. 40, no. 12, pp. 1678-1683, 2005.

[21] R. Jakubovskis, Compatible modelling of cracking, deformation and bond in reinforced concrete structures [Ph.D. thesis], Vilnius Gediminas Technical University, Vilnius, Lithuania, 2015.

[22] G. L. Balazs, "Cracking analysis based on slip and bond stresses," ACI Materials Journal, vol. 90, no. 4, pp. 340-348, 1993.

[23] R. Jakubovskis, G. Kaklauskas, V. Gribniak, A. Weber, and M. Juknys, "Serviceability analysis of concrete beams with different arrangements of GFRP bars in the tensile zone," Journal of Composites for Construction, vol. 18, no. 5, Article ID 04014005 , 2014.

[24] P. Bernardi, R. Cerioni, D. Ferretti, and E. Michelini, "Role of multiaxial state of stress on cracking of RC ties," Engineering Fracture Mechanics, vol. 123, pp. 21-33, 2014. 

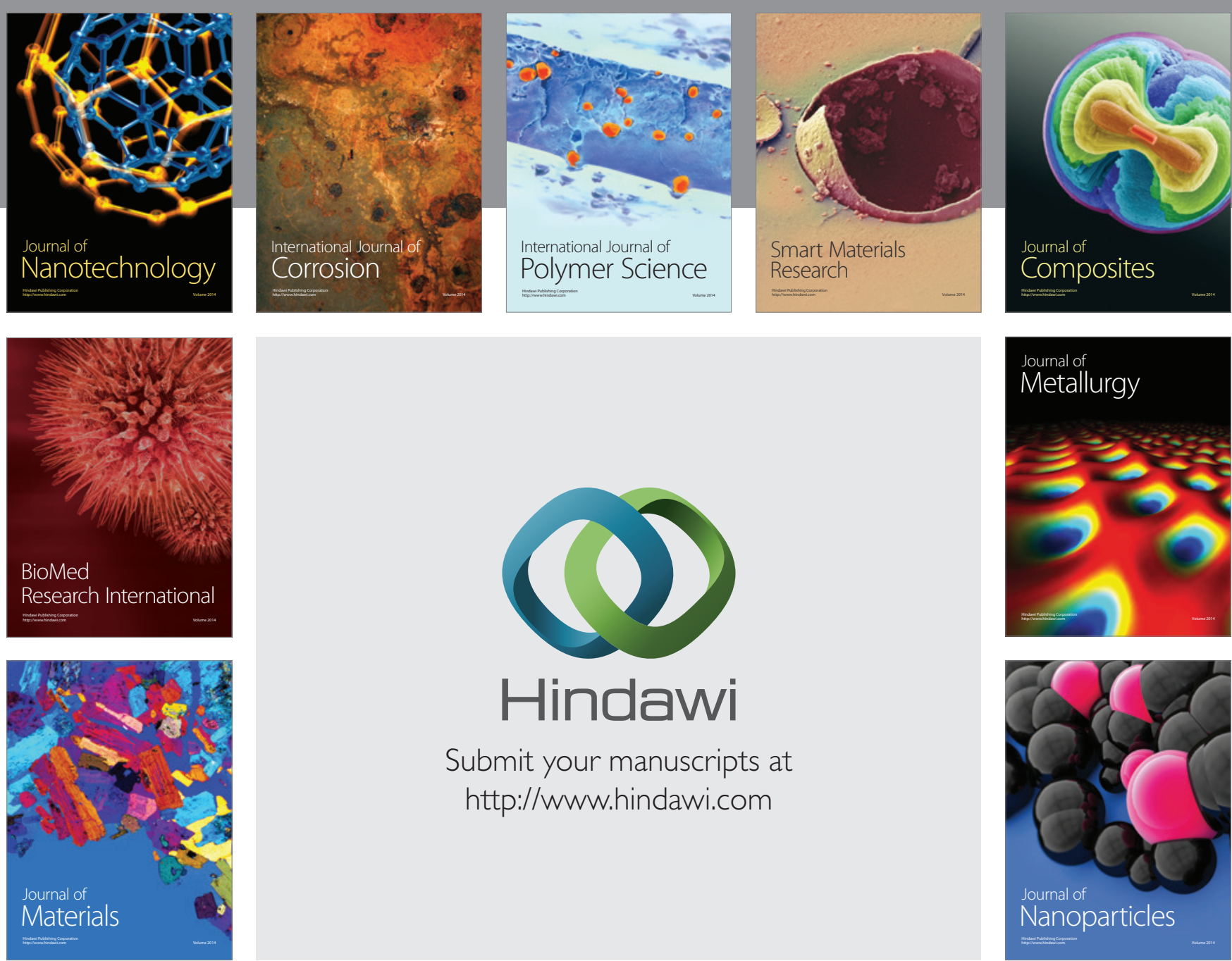

\section{Hindawi}

Submit your manuscripts at

http://www.hindawi.com

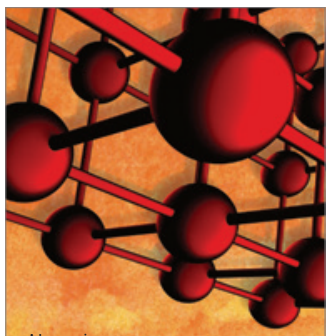

Materials Science and Engineering
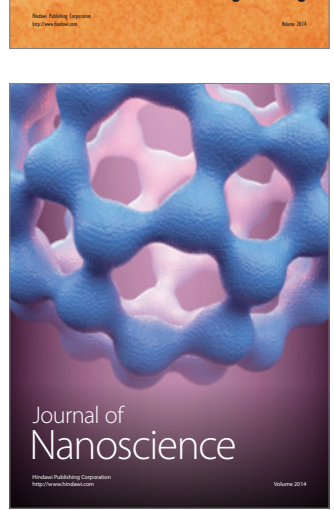
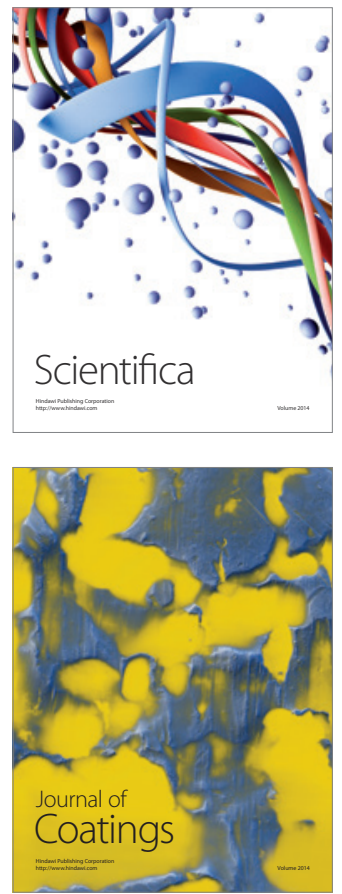
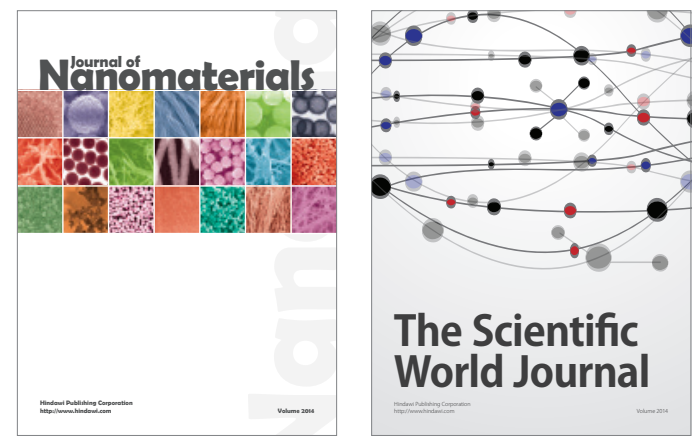

The Scientific World Journal
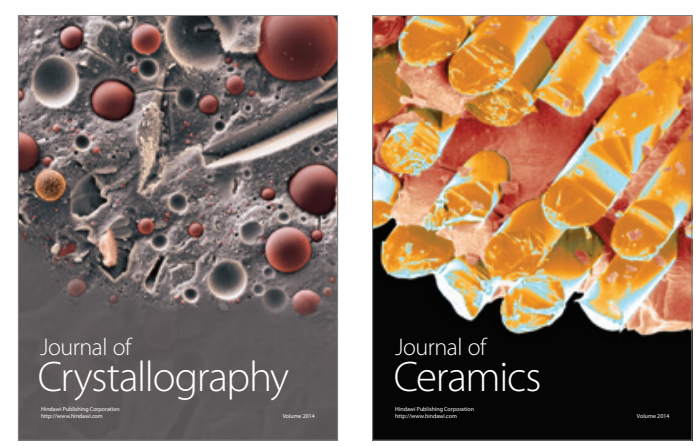
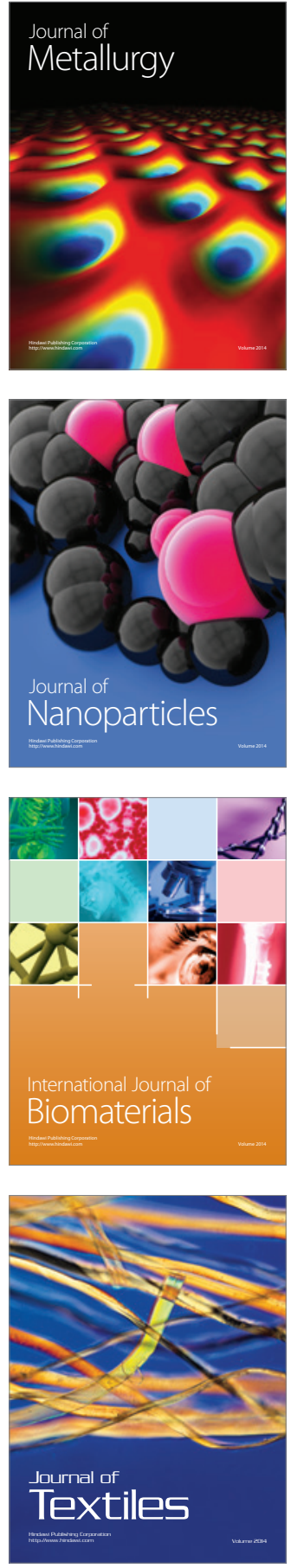